\title{
Second-hand smoke exposure in adulthood and lower respiratory health during 20 year follow up in the European Community Respiratory Health Survey
}

Claudia Flexeder ${ }^{1 *}$ (D), Jan-Paul Zock ${ }^{2,3,4}$, Deborah Jarvis ${ }^{5,6}$, Giuseppe Verlato $^{7}$, Mario Olivieri ${ }^{8}$, Geza Benke $^{9}$, Michael J. Abramson ${ }^{9}$, Torben Sigsgaard ${ }^{10}$, Cecilie Svanes ${ }^{11,12}$, Kjell Torén ${ }^{13}$, Dennis Nowak ${ }^{14,15}$, Rain Jõgi ${ }^{16}$, Jesús Martinez-Moratalla ${ }^{17,18}$, Pascal Demoly ${ }^{19,20}$, Christer Janson ${ }^{21}$, Thorarinn Gislason ${ }^{22,23}$, Roberto Bono ${ }^{24}$, Mathias Holm² ${ }^{25}$ Karl A. Franklin ${ }^{26}$, Judith Garcia-Aymerich ${ }^{2,34}$, Valérie Siroux ${ }^{27}$, Bénédicte Leynaert ${ }^{28}$, Sandra Dorado Arenas ${ }^{29}$, Angelo Guido Corsico ${ }^{30,31}$, Antonio Pereira-Vega ${ }^{32}$, Nicole Probst-Hensch ${ }^{33,34}$, Isabel Urrutia Landa ${ }^{35}$, Holger Schulz ${ }^{1,15}$ and Joachim Heinrich ${ }^{1,14,36}$

\begin{abstract}
Background: Early life exposure to tobacco smoke has been extensively studied but the role of second-hand smoke (SHS) for new-onset respiratory symptoms and lung function decline in adulthood has not been widely investigated in longitudinal studies. Our aim is to investigate the associations of exposure to SHS in adults with respiratory symptoms, respiratory conditions and lung function over 20 years.
\end{abstract}

Methods: We used information from 3011 adults from 26 centres in 12 countries who participated in the European Community Respiratory Health Surveys I-III and were never or former smokers at all three surveys. Associations of SHS exposure with respiratory health (asthma symptom score, asthma, chronic bronchitis, COPD) were analysed using generalised linear mixed-effects models adjusted for confounding factors (including sex, age, smoking status, socioeconomic status and allergic sensitisation). Linear mixed-effects models with additional adjustment for height were used to assess the relationships between SHS exposure and lung function levels and decline.

Results: Reported exposure to SHS decreased in all 26 study centres over time. The prevalence of SHS exposure was 38.7\% at baseline (1990-1994) and 7.1\% after the 20-year follow-up (2008-2011). On average 2.4\% of the study participants were not exposed at the first, but were exposed at the third examination. An increase in SHS exposure over time was associated with doctor-diagnosed asthma (odds ratio (OR): $2.7 ; 95 \%$ confidence interval (95\%-Cl): 1.2-5.9), chronic bronchitis (OR: 4.8; 95\%-Cl: 1.6-15.0), asthma symptom score (count ratio (CR): 1.9; 95\%-Cl: 1.2-2.9) and dyspnoea (OR: 2.7; 95\%-Cl: 1.1-6.7) compared to never exposed to SHS. Associations between increase in SHS exposure and incidence of COPD (OR: 2.0; 95\%-Cl: 0.6-6.0) or lung function ( $\beta$ : $-49 \mathrm{ml} ; 95 \%-C l:-132,35$ for FEV ${ }_{1}$ and $\beta$ : $-62 \mathrm{ml}$; 95\%-Cl: - 165, 40 for FVC) were not apparent.

Conclusion: Exposure to second-hand smoke may lead to respiratory symptoms, but this is not accompanied by lung function changes.

Keywords: Adults, Smoking, Lung function, Asthma, Respiratory symptoms, Bronchitis, ECRHS

\footnotetext{
* Correspondence: claudia.flexeder@helmholtz-muenchen.de

${ }^{1}$ Institute of Epidemiology, Helmholtz Zentrum München - German Research

Center for Environmental Health, Ingolstädter Landstraße 1, 85764

Neuherberg, Germany

Full list of author information is available at the end of the article
}

(c) The Author(s). 2019 Open Access This article is distributed under the terms of the Creative Commons Attribution 4.0 International License (http://creativecommons.org/licenses/by/4.0/), which permits unrestricted use, distribution, and reproduction in any medium, provided you give appropriate credit to the original author(s) and the source, provide a link to the Creative Commons license, and indicate if changes were made. The Creative Commons Public Domain Dedication waiver (http://creativecommons.org/publicdomain/zero/1.0/) applies to the data made available in this article, unless otherwise stated. 


\section{Introduction}

Exposure to second-hand smoke remains one of the most common indoor pollutants worldwide. In an overview paper from 2011 as many as $40 \%$ of children, 35\% of women, and $33 \%$ of men were regularly exposed to second-hand smoke indoors worldwide [1]. Children exposed to passive smoke have deficits in lung growth [2-5]. However, the effect of environmental tobacco smoke on respiratory disorders and lung function has not been widely investigated and the associations are less clear in adults [6-8].

Emerging evidence indicates that exposure to secondhand smoke is related to the development of chronic obstructive pulmonary disease (COPD). Based on three studies [8-10], a meta-analysis [11] found an increased relative risk ( $\mathrm{RR}=1.7,95 \% \mathrm{CI}: 1.4-2.0)$ of $\mathrm{COPD}$ defined by spirometry in people exposed to passive smoking. A link between exposure to second-hand smoke and an accelerated loss of lung function $[6,8]$ was suggested, but the evidence is not strong. Results from cross-sectional analyses of data from middle aged adults participating in the European Community Respiratory Health Survey (ECRHS) showed adverse effects of passive smoking on respiratory symptoms including increased bronchial responsiveness, but the negative association with lung function was not statistically significant [12]. In addition, a variety of early life factors including maternal smoking during pregnancy showed an association with asthma and poor lung function in adulthood [13, 14]. A recent report on life-long exposure to tobacco smoke and lung function trajectories to middle age reported accelerated lung function decline in the exposed subjects [15]. However, some research $[16,17]$ indicates that current or former smokers often suffer from respiratory symptoms, although lung function is still within normal range and the criteria for COPD assessed by spirometry are not met. While there is mounting evidence that second-hand smoke exposure causes respiratory symptoms and lung function deficits at younger ages including young adulthood, the impact in older age groups is less clear.

We aimed to analyse the association of exposure to second-hand smoke with respiratory diseases such as asthma, bronchitis and COPD, asthma-related symptoms and spirometric pulmonary function in long-term follow ups of young and middle aged adults within a large European multicentre study (ECRHS).

\section{Methods}

\section{Study population}

The European Community Respiratory Health Survey (ECRHS) is a multicentre population-based cohort study that began in 1990-1994. Fifty-six centres across Europe and other parts of the world from 25 countries took part. Young adults aged between 20 and 44 years were selected at random from available population-based registers to take part in the survey. It was a two-stage study, with around 200,000 participants in the questionnaire stage 1 , and 26,000 in the clinical stage 2 . In the follow-up survey (ECRHS II) of the clinical stage 2 more than 10,000 adults from 29 centres in 14 countries participated (1998-2001). Detailed descriptions of the methods for ECRHS I and ECRHS II have previously been published $[18,19]$. ECRHS III was the third wave of data collection on the cohort, beginning in 2008 . Those who took part in the clinical stages of ECRHS I and II were again contacted, with responders invited to a local fieldwork centre, situated in an outpatient clinic or lung function laboratory. Information was gathered from standardised interviews by well-trained fieldworkers.

The current analyses were restricted to 3011 never and former smoking adults from the random sample who participated in all three surveys and had information on second-hand smoke exposure at all three examinations.

\section{Definition of smoking and second-hand smoke}

At each survey participants were asked "Have you ever smoked for as long as a year?", and if yes, "Do you smoke now as of one month ago?" Current smokers answered both questions in the affirmative and were excluded. Those who answered the lead question in the negative were classified as never smokers, and exsmokers were those who answered they had smoked but did not in the last month. Smokers and former smokers were asked about duration of smoking and number of cigarettes smoked per day and pack years were calculated. For analytical purposes smoking status was considered as categorical variables never smoker, ex-smoker with less than 15 pack years and ex-smoker with at least 15 pack years.

Exposure to second-hand smoke was assessed by the question "Have you been regularly exposed to tobacco smoke in the last 12 months?". Study participants answering in the affirmative were classified as being exposed to second-hand smoke.

\section{Definition of respiratory health parameters}

Information on the following respiratory symptoms and diseases were collected: physician-diagnosed asthma, chronic bronchitis and COPD, as well as on respiratory symptoms such as wheeze, dyspnoea, cough and sputum. The asthma related symptoms were combined in an asthma score [20]. The following criteria for outcome assessment were used:

- Physician-diagnosed asthma: "Have you ever had asthma?" and "Was this confirmed by a doctor?" were answered in the affirmative. 
- Asthma symptom score: The sum of positive answers to the following five questions, i.e. the asthma score ranges from 0 to 5 , according to Sunyer et al. [20]: 1) "Have you been breathless while wheezing in the last 12 months?"; 2) "Have you been woken up with a feeling of chest tightness in the last 12 months?"; 3) "Have you had an attack of shortness of breath whilst at rest in the last 12 months?"; 4) "Have you had an attack of shortness of breath after activity in the last 12 months?" and 5) "Have you been woken by an attack of shortness of breath in the last 12 months?"

- Nocturnal dyspnoea: "Have you been woken by an attack of shortness of breath at any time during the last twelve months?" was answered in the affirmative.

- Cough: positive answer to at least one of "Have you been woken by an attack of coughing at any time in the last twelve months?", "Do you usually cough first thing in the morning in the winter?" and "Do you usually cough during the day or night in the winter?"

- Sputum: positive answer to at least one of the following questions: "Do you usually bring up phlegm from your chest first thing in the morning in the winter?" and "Do you usually bring up any phlegm from your chest during the day or at night in the winter?"

- Chronic bronchitis: "Do you usually cough during the day or night on most days for as much as three months per year?" and "Do you usually bring up any phlegm from your chest on most days for as much as three months per year?" were answered in the affirmative.

\section{Lung function testing}

Lung function testing was performed by spirometry during the clinical examination according to the ATS/ERS recommendations [21]. Lung function measures were performed in a sitting position while the subjects were wearing nose clips. At least five, but not more than nine, forced expiratory manoeuvres were performed. The maximum forced expiratory volume in $1 \mathrm{~s}\left(\mathrm{FEV}_{1}\right)$ and maximum forced vital capacity (FVC) of the technically acceptable manoeuvres were determined. Spirometric lung function measurements pre-bronchodilation were used in the current analyses. Different spirometers were used across the study centres and follow-up time points within study centres.

Standardised $\mathrm{z}$-scores were calculated based on the reference equations for spirometry from the Global Lung function Initiative (GLI - https://www.ers-education.org/ guidelines/global-lung-function-initiative.aspx) [22] .

The presence of COPD was based on lung function testing. Study participants with a ratio of $\mathrm{FEV}_{1}$ and FVC (measured pre-bronchodilation) below the lower limit of normal (LLN) according to the reference equations for spirometry from the Global Lung function Initiative [22] were classified as COPD patients. It was also defined as the ratio of $\mathrm{FEV}_{1}$ and $\mathrm{FVC}$ (measured pre-bronchodilation) below 0.7 .

\section{Definition of confounders}

Potential confounding variables were assessed by questionnaire or measured at the physical examination. These included sex, age, maternal smoking during pregnancy and/or childhood, paternal smoking during childhood and occupational exposure to dust and fumes. Smoking status was defined as never smoker, ex-smoker with less than 15 pack years and ex-smoker with at least 15 pack years. Socioeconomic status was defined based on the age when fulltime education was completed (less than 17 years, 17 to 20 years and more than 20 years).

Allergen specific IgE was measured at baseline against D. pteronyssinus, cat, timothy grass and Cladosporium using the Pharmacia CAP System and allergic sensitisation was defined as being sensitised to any of these allergens using a cut-off of $0.35 \mathrm{kUA} / \mathrm{L}$.

Height and weight were measured without shoes and in light clothes at the physical examination.

\section{Statistical analyses}

We modelled the longitudinal impact of changes of second-hand smoke exposure on respiratory health outcomes. The effect of change in second-hand smoke exposure over two examinations on lung function parameters as well as respiratory symptoms and diseases at follow-up was analysed separately for ECRHS I-II, ECRHS II-III and ECRHS I-III. Therefore, study participants were categorised into four groups: those not exposed to second-hand smoke at both examinations (reference category); those not exposed to second-hand smoke at the first examination, but at the second examination (SHS increase); those exposed to second-hand smoke at the first examination, but not at the second examination (SHS decrease) and those exposed to second-hand smoke at both examinations (SHS both). Mixed effects logistic regression models and negative binomial mixed effects models with random intercept for study centre were used for respiratory symptoms/ diseases and asthma symptom score, respectively. Linear mixed effects models with random intercept for study centre were used to assess the association of change in second-hand smoke exposure and lung function parameters. All models were adjusted for sex, age, weight, maternal and paternal smoking, exposure to dust/fumes, allergic sensitisation, smoking status and socioeconomic status assessed at baseline and additionally for baseline respiratory symptom/disease and lung function, respectively. 
The models for the association between change in second-hand smoke exposure and lung function were additionally adjusted for height, weight squared and age squared (to model the non-linear relationship of weight and age with lung function). All continuous covariates were standardised (with mean 0 and variance 1 ).

The associations between exposure to second-hand smoke at baseline and lung function parameters at the three surveys were analysed to evaluate the effect of second-hand smoke exposure on lung function over time. Therefore, linear mixed effects models were fitted with random intercept for study participants nested in the study centre, and an interaction term between second-hand smoke exposure and time of follow-up, i.e. the time between the particular examinations, was included to model the impact of second-hand smoke exposure on lung function decline [23].

Interaction terms with sex, maternal smoking and paternal smoking were tested. Results from stratified analyses are therefore reported. In addition, sensitivity analyses restricted to never smokers at all three surveys $(n=1974$ lifetime never smokers) were performed. For the association between change in second-hand smoke exposure over time and lung function at follow-up, additional analyses using percent predicted values according to the Global Lung function Initiative [22] were conducted.

The results for the association between second-hand smoke exposure with respiratory symptoms and diseases are presented as odds ratio (OR) with corresponding 95\% confidence interval (CI), whereas the results for the association of second-hand smoke exposure with lung function parameters are presented as regression coefficients $(\beta)$ with corresponding $95 \%$ CI. For the asthma symptom score, the results are presented as count ratio (CR) with corresponding 95\% CI.

All analyses were performed using the statistical software $R$, version 3.4.3 [24], and the R packages "Ime4" and "ImerTest".

\section{Results}

Description of study population and temporal changes of second-hand smoke exposure and lung function

The analyses were based on 3011 non-smoking adults from 26 study centres who participated in all three surveys and had information on second-hand smoke exposure at all three examinations (Fig. 1). The prevalence of reported exposure to second-hand smoke decreased in all participating study centres from ECRHS I to III (Table 1). Overall, at the first examination, $38.7 \%$ were exposed to second-hand smoke, $23.0 \%$ at the second examination and $7.1 \%$ at the third examination. The prevalences were highest in Spain.

The prevalence of respiratory symptoms and diseases and the distribution of lung function parameters and confounding variables in each survey are summarised in Table 2.

Table 3 shows the change in second-hand smoke exposure from ECRHS I-II, ECRHS II-III as well as ECRHS I-III. Almost 7\% (ECRHS I-II) and 2.5\% (ECRHS II-III) of the study participants were not exposed at the first, but were exposed at the second examination.

The distribution of the lung function parameters as well as the annual decline are summarised in Table 4. All lung function parameters $\left(\mathrm{FEV}_{1}, \mathrm{FVC}\right.$ and $\left.\mathrm{FEV}_{1} / \mathrm{FVC}\right)$ decreased over time, with greater decline in the second 10 year follow-up period (ECRHS II-III; $42 \mathrm{ml} /$ year decline in $\mathrm{FEV}_{1}$ ) compared to the first 10 year period (ECRHS I-II; $24 \mathrm{ml} /$ year decline in $\mathrm{FEV}_{1}$ ) as expected with ageing of the population.

\section{Adjusted associations between change in second-hand smoke exposure over time and respiratory symptoms and diseases at follow-up [ECRHS I-II, ECRHS II-III and ECRHS I-III]}

Adjusted time variant analysis of second-hand smoke exposure showed that those reporting increased secondhand smoke exposure had increased risks for the development of doctor-diagnosed asthma, chronic bronchitis and increased asthma symptom score, reaching conventional levels of significance from ECRHS II-III as well as from ECRHS I-III overall (Fig. 2). However, compared to those not exposed on both occasions there was no evidence that those reporting exposure on both occasions had an increased risk of asthma or chronic bronchitis. However, asthma score did increase in this group compared to the non-exposed. An increased risk of nocturnal dyspnoea was observed only for those reporting increased second-hand smoke exposure between the first and the third survey but not for those exposed at both surveys.

Spirometrically defined COPD was not statistically significantly associated with changes in second-hand smoke exposure at any of the examined periods over the 20 years after adjustment for several selected confounders (Fig. 2).

\section{Adjusted associations between change in second-hand smoke exposure over time and lung function parameters at follow-up}

There was no association of second-hand smoke exposure with $\mathrm{FEV}_{1}$.

Study participants exposed to second-hand smoke at the first as well as at the second survey (ECRHS I-II) had a reduced forced vital capacity at the second survey (approximately $50 \mathrm{ml}$ ) compared to those not exposed to second-hand smoke at these two surveys (Fig. 3) - but there was no clear or consistent pattern of association over the entire study period.

Similarly the ratio of $\mathrm{FEV}_{1} / \mathrm{FVC}$ showed associations with increased second-hand smoke exposure from 


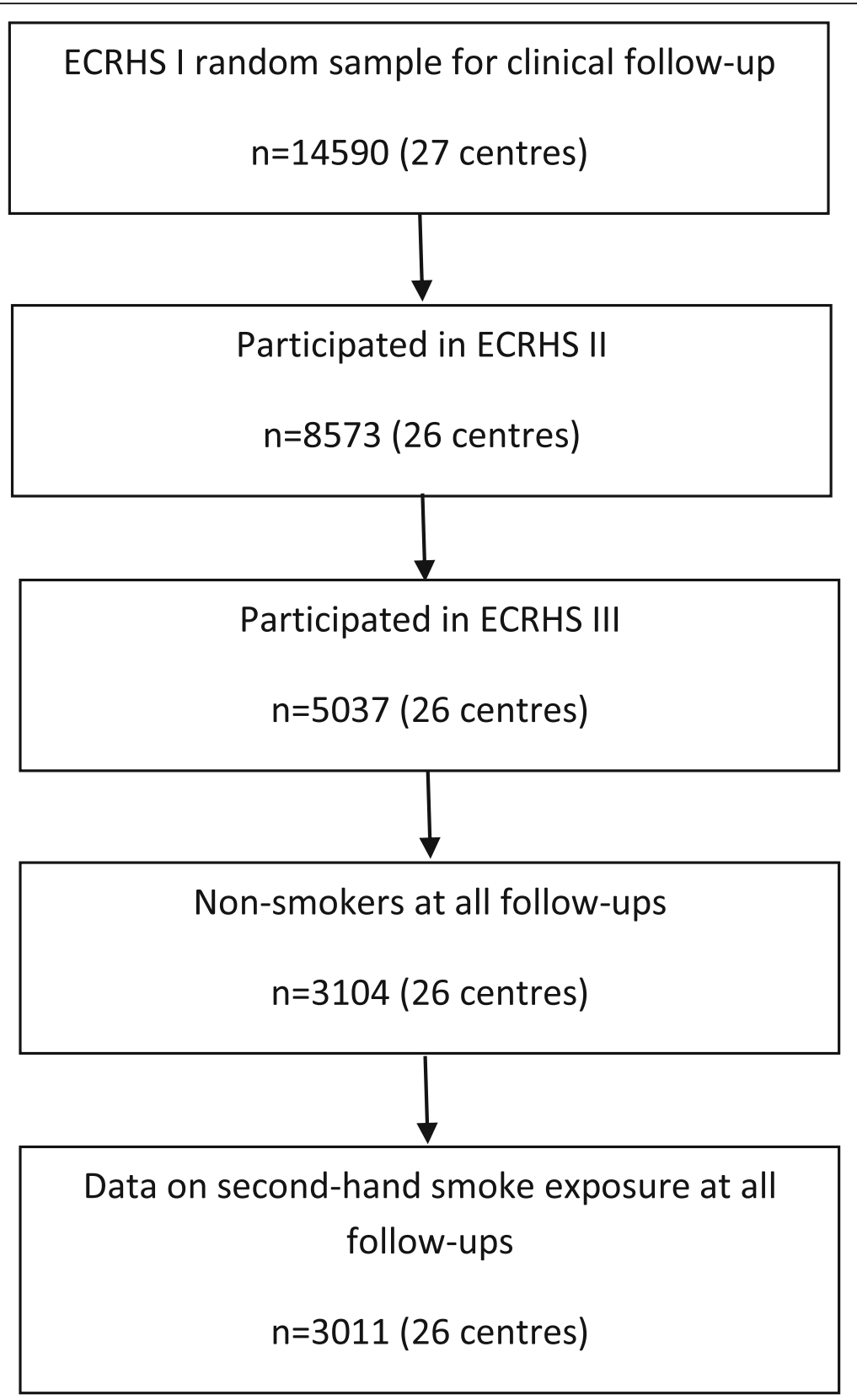

Fig. 1 Flow chart of study population

ECRHS I-II but no consistent pattern when the data were examined over the entire period.

Sensitivity analyses using percent predicted values according to the Global Lung function Initiative showed comparable results (Additional file 1: Table S1).

\section{Adjusted associations between second-hand smoke} exposure at the first examination and lung function as well as lung function decline

The associations of exposure to second-hand smoke at the first examination (ECRHS I) with lung function as well as lung function decline from ECRHS I-III are summarised in Table 5. Exposure to second-hand smoke at the first examination resulted in reduced $\mathrm{FEV}_{1}$ and $\mathrm{FVC}$ over time, with stronger effects for males compared to females. It also shows that those exposed to second-hand smoke at the first examination had a slightly slower decline in lung function compared to those not exposed.

Sensitivity analyses restricted to lifetime never smokers, i.e. participants who were never smokers at all three surveys showed comparable results (data not shown). 
Table 1 Number of participants and prevalence of second-hand smoke (SHS) exposure by study centre

\begin{tabular}{|c|c|c|c|c|}
\hline & $n$ & SHS exposure in ECRHS I, \% & SHS exposure in ECRHS II, \% & SHS exposure in ECRHS III, \% \\
\hline Antwerp South (Belgium) & 104 & $48.1(50 / 104)$ & $32.7(34 / 104)$ & $7.7(8 / 104)$ \\
\hline Antwerp City (Belgium) & 99 & $50.5(50 / 99)$ & $36.4(36 / 99)$ & $9.1(9 / 99)$ \\
\hline Hamburg (Germany) & 110 & $46.4(51 / 110)$ & $26.4(29 / 110)$ & $10.0(11 / 110)$ \\
\hline Erfurt (Germany) & 107 & $38.3(41 / 107)$ & $26.2(28 / 107)$ & $6.5(7 / 107)$ \\
\hline Barcelona (Spain) & 54 & $64.8(35 / 54)$ & $40.7(22 / 54)$ & $14.8(8 / 54)$ \\
\hline Galdakao (Spain) & 139 & $74.1(103 / 139)$ & $51.1(71 / 139)$ & $23.0(32 / 139)$ \\
\hline Albacete (Spain) & 69 & $68.1(47 / 69)$ & $42.0(29 / 69)$ & $15.9(11 / 69)$ \\
\hline Oviedo (Spain) & 50 & $56.0(28 / 50)$ & $52.0(26 / 50)$ & $28.0(14 / 50)$ \\
\hline Huelva (Spain) & 43 & $58.1(25 / 43)$ & $53.5(23 / 43)$ & $18.6(8 / 43)$ \\
\hline Bordeaux (France) & 63 & $50.8(32 / 63)$ & $28.6(18 / 63)$ & $6.3(4 / 63)$ \\
\hline Grenoble (France) & 212 & $34.0(72 / 212)$ & $25.5(54 / 212)$ & $6.6(14 / 212)$ \\
\hline Montpellier (France) & 88 & $34.1(30 / 88)$ & $13.6(12 / 88)$ & $1.1(1 / 88)$ \\
\hline Paris (France) & 186 & $40.3(75 / 186)$ & $33.3(62 / 186)$ & $4.8(9 / 186)$ \\
\hline Pavia (Italy) & 51 & $64.7(33 / 51)$ & $47.1(24 / 51)$ & $2.0(1 / 51)$ \\
\hline Turin (Italy) & 39 & $51.3(20 / 39)$ & $38.5(15 / 39)$ & $12.8(5 / 39)$ \\
\hline Verona (Italy) & 57 & $35.1(20 / 57)$ & $17.5(10 / 57)$ & $7.0(4 / 57)$ \\
\hline Ipswich (UK) & 93 & $31.2(29 / 93)$ & $20.4(19 / 93)$ & $7.5(7 / 93)$ \\
\hline Norwich (UK) & 88 & $36.4(32 / 88)$ & $11.4(10 / 88)$ & $3.4(3 / 88)$ \\
\hline Reykjavik (Iceland) & 197 & $47.2(93 / 197)$ & $26.4(52 / 197)$ & $7.1(14 / 197)$ \\
\hline Bergen (Norway) & 186 & $30.1(56 / 186)$ & $11.8(22 / 186)$ & $5.4(10 / 186)$ \\
\hline Gothenburg (Sweden) & 149 & $46.3(69 / 149)$ & $6.7(10 / 149)$ & $2.7(4 / 149)$ \\
\hline Umea (Sweden) & 162 & $22.2(36 / 162)$ & $8.6(14 / 162)$ & $4.9(8 / 162)$ \\
\hline Uppsala (Sweden) & 216 & $18.1(39 / 216)$ & $3.7(8 / 216)$ & $1.4(3 / 216)$ \\
\hline Basel (Switzerland) & 221 & $24.4(54 / 221)$ & $16.3(36 / 221)$ & $6.8(15 / 221)$ \\
\hline Melbourne (Australia) & 165 & $13.3(22 / 165)$ & $8.5(14 / 165)$ & $1.8(3 / 165)$ \\
\hline Tartu (Estonia) & 63 & $34.9(22 / 63)$ & $25.4(16 / 63)$ & $3.2(2 / 63)$ \\
\hline Overall & 3011 & $38.7(1164 / 3011)$ & $23.0(694 / 3011)$ & $7.1(215 / 3011)$ \\
\hline
\end{tabular}

\section{Discussion}

This study investigated the association of exposure to second-hand smoke with respiratory symptoms and diagnoses, as well as lung function and lung function decline in never and former smoking participants in ECRHS I-III. We show that the proportion of the studied population exposed to second-hand smoke fell markedly over the follow-up period of 20 years. Individuals who became exposed to second-hand smoke over time were at increased risk of doctor-diagnosed asthma, chronic bronchitis as well as a higher asthma symptom score. Associations between increase in second-hand smoke exposure and incidence of COPD or lung function were not apparent.

Comparison with results from other epidemiology studies Only a few studies have examined the association of exposure to second-hand smoke with onset of asthma in adulthood. In the prospective U.S. Black Women's
Health Study, Coogan et al. observed a positive association of passive smoke exposure with the incidence of adult-onset asthma over 15 years of follow-up in 46,182 women aged 21 to 69 years at baseline [25]. Non-smoking study participants who were exposed to second-hand smoke had a $21 \%$ increase (adjusted HR: 1.2; 95\%-CI: 1.0-1.5) in asthma incidence compared to those not exposed. Similar findings were observed in two Finnish population-based case-control studies [26, 27]. Exposure to second-hand smoke at the workplace or at home increased the risk for the development of asthma during a period of 2.5 years [27]. In our study, an increase in second-hand smoke exposure over time was associated with an increased risk of doctor-diagnosed asthma. An increased asthma symptom score was observed for those reporting increased second-hand smoke exposure as well as for those exposed on both occasions. A decrease in second-hand smoke exposure was also associated with an increased asthma symptom score. However, this association was not 
Table 2 Prevalence of respiratory symptoms and diseases and distribution of lung function parameters and confounding variables ${ }^{\mathrm{a}}$

\begin{tabular}{|c|c|c|c|c|c|c|}
\hline & \multicolumn{2}{|l|}{ ECRHS I } & \multicolumn{2}{|l|}{ ECRHS II } & \multicolumn{2}{|l|}{ ECRHS III } \\
\hline & $\begin{array}{l}\text { SHS exposed } \\
(n=1164)\end{array}$ & $\begin{array}{l}\text { SHS non-exposed } \\
(n=1847)\end{array}$ & $\begin{array}{l}\text { SHS exposed } \\
(n=694)\end{array}$ & $\begin{array}{l}\text { SHS non-exposed } \\
(n=2317)\end{array}$ & $\begin{array}{l}\text { SHS exposed } \\
(n=215)\end{array}$ & $\begin{array}{l}\text { SHS non-exposed } \\
(n=2796)\end{array}$ \\
\hline Sex, female & $52.0(605 / 1164)$ & $55.5(1025 / 1847)$ & $51.9(360 / 694)$ & $54.8(1270 / 2317)$ & $58.6(126 / 215)$ & $53.8(1504 / 2796)$ \\
\hline Age, years & $33.8(7.5)$ & $35.1(6.9)$ & $43.5(7.3)$ & $43.3(7.1)$ & $53.8(6.9)$ & $54.7(7.2)$ \\
\hline \multicolumn{7}{|c|}{ Age completed full time education } \\
\hline$<17$ years & $19.4(212 / 1093)$ & $13.8(232 / 1686)$ & $24.7(160 / 649)$ & $13.3(284 / 2130)$ & $29.6(59 / 199)$ & $14.9(385 / 2580)$ \\
\hline $17-20$ years & $39.1(427 / 1093)$ & $33.6(567 / 1686)$ & $39.8(258 / 649)$ & $34.6(736 / 2130)$ & $39.7(79 / 199)$ & $35.5(915 / 2580)$ \\
\hline$>20$ years & $41.5(454 / 1093)$ & $52.6(887 / 1686)$ & $35.6(231 / 649)$ & $52.1(1110 / 2130)$ & $30.7(61 / 199)$ & $49.6(1280 / 2580)$ \\
\hline Height, cm & $170.4(9.8)$ & $170.6(9.5)$ & $169.6(10.0)$ & $170.9(9.5)$ & $167.2(10.2)$ & $170.1(9.7)$ \\
\hline Weight, kg & $70.2(14.0)$ & $68.7(13.2)$ & $74.5(15.0)$ & $73.6(14.9)$ & $77.7(14.2)$ & $77.6(16.1)$ \\
\hline Paternal smoking & $63.3(714 / 1128)$ & $58.2(1059 / 1819)$ & $67.2(452 / 673)$ & $58.1(1321 / 2274)$ & $72.9(153 / 210)$ & $59.2(1620 / 2737)$ \\
\hline Maternal smoking & $20.5(237 / 1155)$ & $20.3(373 / 1834)$ & $17.8(123 / 690)$ & $21.2(487 / 2299)$ & $18.2(39 / 214)$ & $20.6(571 / 2775)$ \\
\hline $\begin{array}{l}\text { Allergic sensitisation, } \\
\text { lgE }\end{array}$ & $26.5(267 / 1007)$ & $33.8(538 / 1593)$ & $26.0(151 / 581)$ & $32.4(654 / 2019)$ & $28.4(50 / 176)$ & $31.1(755 / 2424)$ \\
\hline Dust/fumes exposure & $41.8(484 / 1159)$ & $35.7(653 / 1828)$ & $42.7(296 / 694)$ & $39.0(904 / 2316)$ & $38.5(77 / 200)$ & $22.1(572 / 2583)$ \\
\hline Ex-smoker & $31.2(363 / 1164)$ & $28.7(531 / 1847)$ & $33.3(231 / 694)$ & $29.5(684 / 2317)$ & $31.6(68 / 215)$ & $29.0(810 / 2796)$ \\
\hline \multicolumn{7}{|l|}{ Smoking status } \\
\hline Never smoker & $69.2(801 / 1158)$ & $71.4(1316 / 1844)$ & $67.9(463 / 682)$ & $73.0(1633 / 2236)$ & $70.0(147 / 210)$ & $73.3(1986 / 2709)$ \\
\hline $\begin{array}{l}\text { Ex-smoker with }<15 \\
\text { pack-years }\end{array}$ & $23.2(269 / 1158)$ & $22.3(412 / 1844)$ & $21.6(147 / 682)$ & $21.2(474 / 2236)$ & $16.2(34 / 210)$ & $20.1(544 / 2709)$ \\
\hline $\begin{array}{l}\text { Ex-smoker with > = } 15 \\
\text { pack-years }\end{array}$ & $7.6(88 / 1158)$ & $6.3(116 / 1844)$ & $10.6(72 / 682)$ & $5.8(129 / 2236)$ & $13.8(29 / 210)$ & $6.6(179 / 2709)$ \\
\hline $\begin{array}{l}\text { Asthma, doctor- } \\
\text { diagnosed }\end{array}$ & $7.1(82 / 1160)$ & $7.4(136 / 1846)$ & $10.4(72 / 694)$ & $10.8(250 / 2312)$ & $15.0(32 / 213)$ & $13.8(385 / 2792)$ \\
\hline Chronic bronchitis & $1.4(16 / 1162)$ & $1.3(24 / 1846)$ & $2.3(16 / 693)$ & $1.2(27 / 2314)$ & $4.2(9 / 215)$ & $2.1(59 / 2789)$ \\
\hline $\mathrm{COPD}, \mathrm{FEV}_{1} / \mathrm{FVC}<0.7$ & $2.7(29 / 1078)$ & $3.4(59 / 1731)$ & $2.5(16 / 630)$ & $4.4(89 / 2042)$ & $9.3(18 / 193)$ & $10.8(264 / 2448)$ \\
\hline $\begin{array}{l}\text { COPD, FEV } / / F V C< \\
\text { GLI LLN }\end{array}$ & $4.6(50 / 1077)$ & $4.5(78 / 1731)$ & $2.2(14 / 629)$ & $3.8(77 / 2038)$ & $5.7(11 / 193)$ & $5.8(142 / 2445)$ \\
\hline \multicolumn{7}{|l|}{ Asthma symptom score } \\
\hline 0 & $74.8(866 / 1157)$ & $76.0(1392 / 1831)$ & $67.9(468 / 689)$ & $75.0(1723 / 2298)$ & $65.6(137 / 209)$ & $72.7(1974 / 2714)$ \\
\hline 1 & $14.1(163 / 1157)$ & $13.0(238 / 1831)$ & $18.3(126 / 689)$ & $13.6(313 / 2298)$ & $16.7(35 / 209)$ & $16.8(455 / 2714)$ \\
\hline 2 & $5.7(66 / 1157)$ & $5.4(99 / 1831)$ & $6.7(46 / 689)$ & $5.9(136 / 2298)$ & $7.7(16 / 209)$ & $6.0(163 / 2714)$ \\
\hline 3 & $2.9(33 / 1157)$ & $2.8(51 / 1831)$ & $3.5(24 / 689)$ & $3.1(72 / 2298)$ & $4.8(10 / 209)$ & $2.5(67 / 2714)$ \\
\hline 4 & $1.6(18 / 1157)$ & $1.6(30 / 1831)$ & $2.5(17 / 689)$ & $1.6(36 / 2298)$ & $3.3(7 / 209)$ & $1.0(26 / 2714)$ \\
\hline 5 & $1.0(11 / 1157)$ & $1.1(21 / 1831)$ & $1.2(8 / 689)$ & $0.8(18 / 2298)$ & $1.9(4 / 209)$ & $1.1(29 / 2714)$ \\
\hline Dyspnoea & $4.6(54 / 1163)$ & $4.9(90 / 1847)$ & $6.5(45 / 694)$ & $5.2(120 / 2310)$ & $9.0(19 / 211)$ & $5.2(142 / 2743)$ \\
\hline Cough & $33.6(390 / 1159)$ & $29.7(547 / 1842)$ & $35.3(244 / 692)$ & $31.7(733 / 2312)$ & $40.1(85 / 212)$ & $33.7(936 / 2778)$ \\
\hline Sputum & $11.2(129 / 1153)$ & $10.1(185 / 1827)$ & $12.0(83 / 692)$ & $10.0(230 / 2298)$ & $15.2(32 / 211)$ & $10.9(302 / 2769)$ \\
\hline $\mathrm{FEV}_{1}, \mathrm{ml}$ & 3800 (824) & 3781 (835) & 3522 (805) & 3595 (819) & 3028 (756) & 3123 (778) \\
\hline FVC, ml & 4573 (1032) & 4591 (1058) & $4306(1000)$ & 4458(1030) & 3904 (995) & 4063 (993) \\
\hline $\mathrm{FEV}_{1} / \mathrm{FVC}, \%$ & $83.5(6.7)$ & $82.8(6.5)$ & $82.1(5.9)$ & $80.9(6.1)$ & $77.6(5.6)$ & $77.0(5.7)$ \\
\hline
\end{tabular}

${ }^{a}$ stratified by exposure to second-hand smoke (SHS) and presented as $\%(\mathrm{n} / \mathrm{N})$ for categorical variables and mean (SD) for continuous variables, respectively

consistent, being only recorded from ECRHS I to ECRHS II, and the strength of the association was rather low. Of note, the ECRHS questionnaire had not been specifically devised to assess changes in respiratory symptoms after smoking cessation or decrease in second-hand smoke exposure. Overall our study findings are consistent with results of the few other studies on second-hand smoke and asthma development in adults.

Previous studies have investigated the association of exposure to second-hand smoke with respiratory symptoms 
Table 3 Second-hand smoke (SHS) exposure in ECRHS I-II, ECRHS II-III and ECRHS I-III

\begin{tabular}{llll}
\hline & Changes between ECRHS I and II & Changes between ECRHS II and III & Changes between ECRHS I and III \\
\hline No SHS exposure at both examinations & $54.4(1639 / 3011)$ & $74.5(2243 / 3011)$ & $58.9(1774 / 3011)$ \\
$\begin{array}{l}\text { No SHS exposure at first examination but } \\
\text { at second examination }\end{array}$ & $6.9(208 / 3011)$ & $2.5(74 / 3011)$ & $2.4(73 / 3011)$ \\
$\begin{array}{l}\text { SHS exposure at first examination but not } \\
\text { at second examination }\end{array}$ & $22.5(678 / 3011)$ & $18.4(553 / 3011)$ & $33.9(1022 / 3011)$ \\
SHS exposure at both examinations & $16.1(486 / 3011)$ & $4.7(141 / 3011)$ & $4.7(142 / 3011)$ \\
\hline
\end{tabular}

apresented as \% (n/N)

and diseases, especially COPD. For instance, Eisner et al. [6] analysed the effect of lifetime exposure to second-hand smoke on the risk for the development of COPD in 2112 adults (including current, former and never smokers) aged 55 to 75 years in the U.S. It showed a positive significant association between cumulative exposure to second-hand smoke at home (adjusted OR: 1.6; 95\%-CI: 1.1-2.2) as well as at work (adjusted OR: 1.4; 95\%-CI: 1.0-1.8) with self-reported doctor-diagnosed COPD. A Chinese study [8] also investigated the relationship of self-reported density and duration of exposure to passive smoking with respiratory symptoms (cough, phlegm and shortness of breath) and COPD ( $\mathrm{FEV}_{1} / \mathrm{FVC}<0.7$ measured pre-bronchodilation) based on data from 15,379 never smoking adults in the Guangzhou Biobank Cohort Study. Exposure to second-hand smoke at home and at work was significantly associated with an increased risk of COPD (adjusted OR: 1.5 ; 95\%-CI: $1.2-1.9$ ) and any respiratory symptoms (adjusted OR: 1.2; 95\%-CI: 1.1-1.3).

An increased risk of COPD, defined using the fixed ratio of $\mathrm{FEV}_{1} / \mathrm{FVC}<0.7$ measured post-bronchodilation, was seen in those with second-hand smoke exposure in a study [28] of 2182 lifelong never smokers taking part in the Obstructive Lung Disease in Northern Sweden (OLIN) studies. Exposure to second-hand smoke was categorised into several groups based on previous and current exposure to second-hand smoke at home and at work. The strongest associations were seen in those ever exposed at home and at both previous and current work (adjusted OR: 3.8; 95\%-CI: 1.3-11.2) as well as for those currently exposed at home and at both previous and current work (adjusted OR: 5.7; 95\%-CI: 1.5-22.5). A significant dose dependent relationship of exposure to second-hand smoke with mortality from different diseases, including COPD amongst other causes of death, could be shown in another study [10]. In contrast, a study conducted by Chan-Yeung et al. [9] found no association between exposure to second-hand smoke and an increased risk for COPD in a small sex- and age-matched case-control study comprising 289 patients and controls, respectively, in Hong Kong, China.

The different associations between exposure to second-hand smoke and COPD in the above studies might be due to the different definition of COPD as some studies used questionnaire-based information whereas others used spirometric measurements. Furthermore, some studies were restricted to lifetime never smokers compared to studies also including active smokers. We have shown no significant association between increase in second-hand smoke exposure and incidence of COPD based on lung function testing in our study, which was restricted to never and former smokers. The different observed associations might also be due to residual confounding in some studies or potential misclassification of self-reported exposure to second-hand smoke in our study.

Another study, based on Taiwan's National Health Insurance Bureau claims data, investigated the association of exposure to second-hand smoke and chronic bronchitis in women [29] and showed that women who were exposed to second-hand smoke had a 3.7 (95\%-CI: 1.2-11.3) higher risk of chronic bronchitis compared to those not exposed to second-hand smoke. Furthermore, exposure to second-hand smoke was also associated with mild (adjusted OR: 1.8; 95\%-CI: 1.1-2.9) and moderate (adjusted OR: 3.8; 95\%-CI: 1.7-8.6) COPD as defined by GOLD.

We have shown a significant positive association of new exposure to second-hand smoke between two surveys with chronic bronchitis at follow-up, defined as having cough and sputum. However there was no evidence of a decrease in chronic bronchitis if exposure to second-hand smoke stopped over the same time frame. In addition, exposure to second-hand smoke was not

Table 4 Distribution of lung function parameters and annual change ${ }^{a}$

\begin{tabular}{lllllll}
\hline & ECRHS I & ECRHS II & ECRHS III & $\begin{array}{l}\text { Difference between ECRHS I } \\
\text { and II (ml or \% per year) }\end{array}$ & $\begin{array}{l}\text { Difference between ECRHS II } \\
\text { and III (ml or \% per year) }\end{array}$ & $\begin{array}{l}\text { Difference between ECRHS I } \\
\text { and III (ml or \% per year) }\end{array}$ \\
\hline FEV $_{1}(\mathrm{ml})$ & $3789(830)$ & $3578(816)$ & $3116(777)$ & $-24(36)$ & $-42(26)$ & $-34(17)$ \\
$\mathrm{FVC}(\mathrm{ml})$ & $4584(1048)$ & $4422(1025)$ & $4052(994)$ & $-19(45)$ & $-34(35)$ & $-27(21)$ \\
$\mathrm{FEV}_{1} / \mathrm{FVC}(\%)$ & $83(7)$ & $81(6)$ & $77(6)$ & $-0.2(0.5)$ & $-0.4(0.4)$ & $-0.3(0.3)$ \\
\hline
\end{tabular}

presented as mean (SD) 


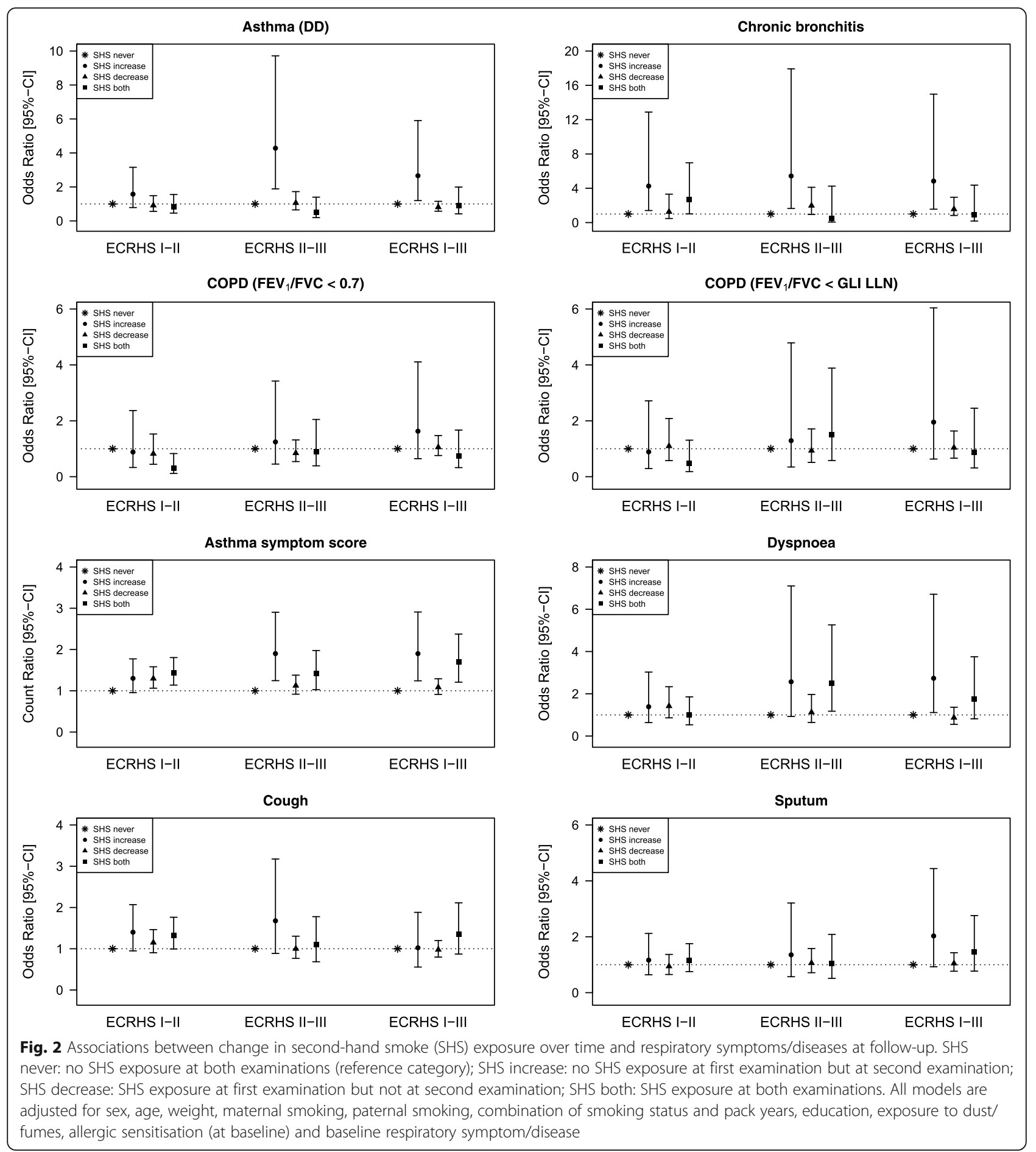

associated with COPD defined by a ratio of $\mathrm{FEV}_{1} / \mathrm{FVC}$ below $0.7[30,31]$. According to the original classification of COPD from the Global Initiative for Chronic Obstructive Lung Disease (GOLD) in 2001 [32], stage 0 "at risk" is characterised by chronic symptoms (sputum production and cough) with still normal spirometry, i.e. the ratio between $\mathrm{FEV}_{1}$ and FVC of at least 0.7. This GOLD stage 0 would be similar to the definition of chronic bronchitis used in this analysis which requires a positive answer to both the question on cough and the question on sputum, independent of lung function. Moreover, the overlap between chronic bronchitis and COPD defined by spirometry was quite small in this study. As an effect of exposure to second-hand smoke was found in this study only for chronic bronchitis, but not for COPD, one might speculate that these results 


\section{FEV $_{1}$}

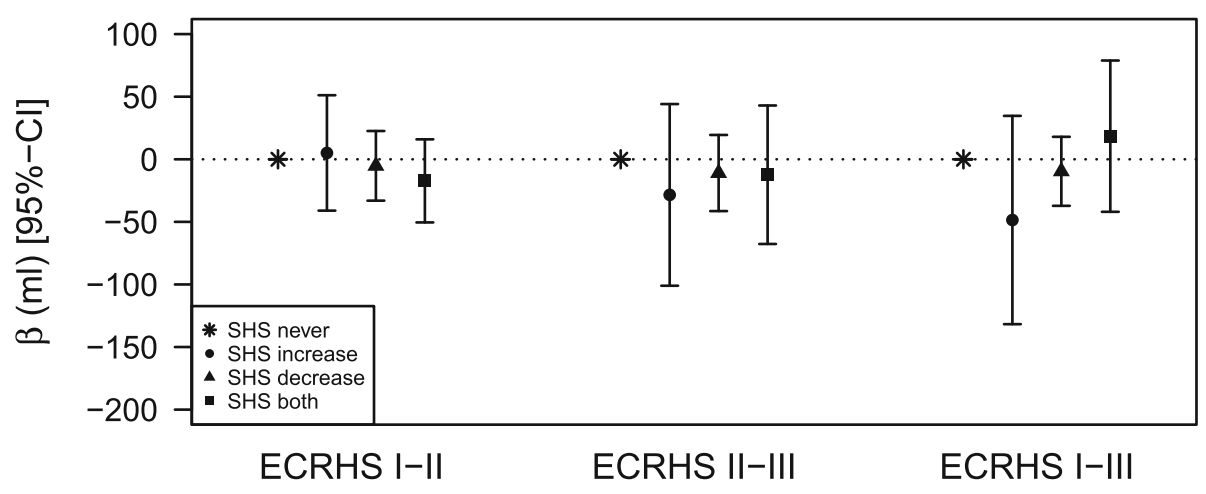

FVC

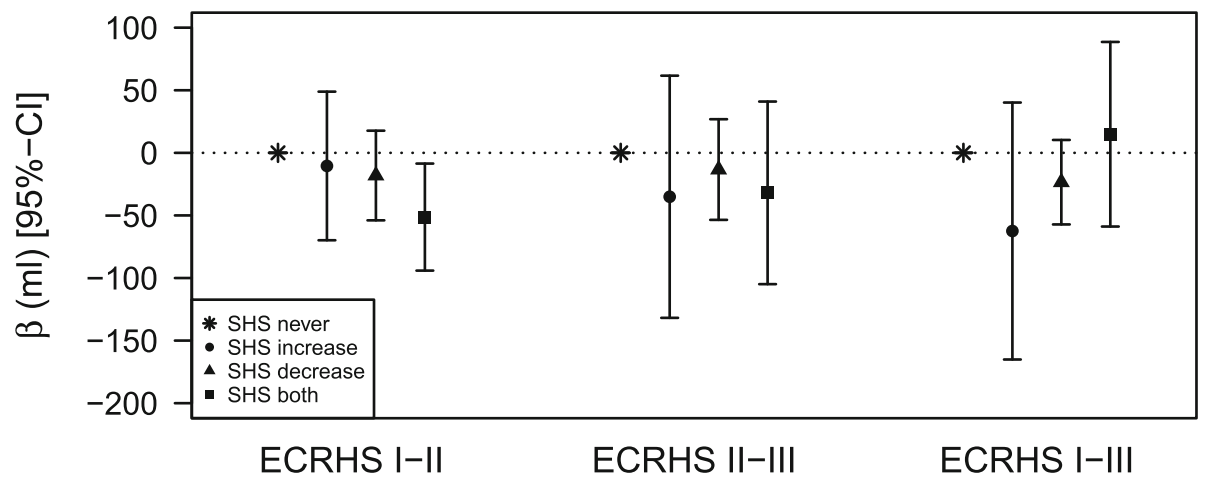

$\mathrm{FEV}_{1} / \mathrm{FVC}$

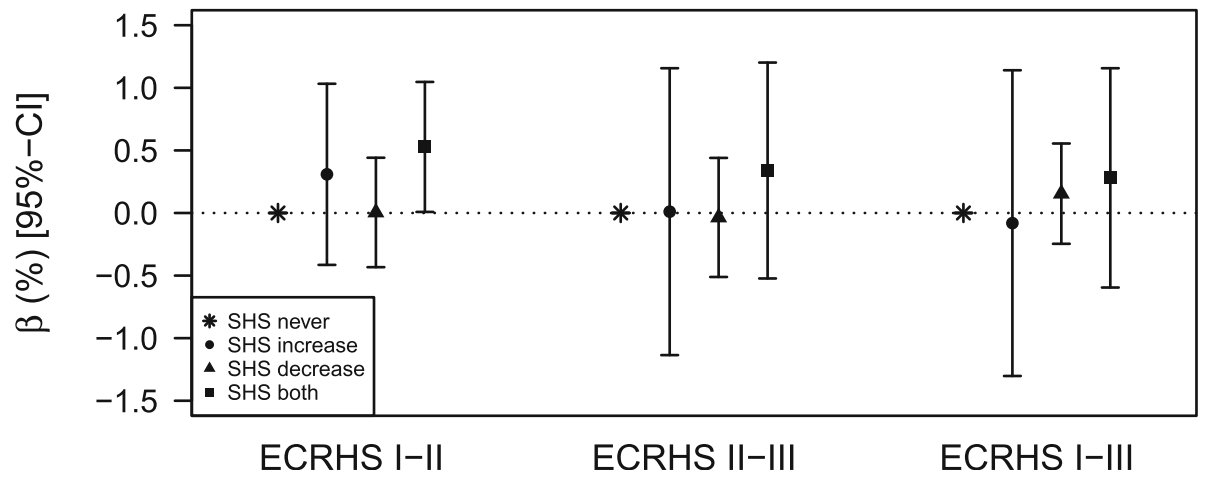

Fig. 3 Associations between change in second-hand smoke (SHS) exposure over time and lung function at follow-up. SHS never: no SHS exposure at both examinations (reference category); SHS increase: no SHS exposure at first examination but at second examination; SHS decrease: SHS exposure at first examination but not at second examination; SHS both: SHS exposure at both examinations. All models are adjusted for sex, age, age squared, weight, weight squared, height, maternal smoking, paternal smoking, combination of smoking status and pack years, education, exposure to dust/ fumes, allergic sensitisation (at baseline) and baseline lung function

indicate a transient effect, but not structural changes in the airways as would be common in COPD patients.

Although COPD is generally considered a disease characterised by a progressive, gradually accelerating decline in $\mathrm{FEV}_{1}$ Macklem has pointed out that increase in residual volume (RV) is the first functional abnormality in chronic bronchitis [33]. Thus, gas trapping with reduction of FVC is an early abnormality because RV increases more than the total lung capacity (TLC). The observed decrease in $\mathrm{FEV}_{1}$ occurs because of a reduction 
Table 5 Associations between second-hand smoke (SHS) exposure at the first examination and lung function and decline

\begin{tabular}{|c|c|c|c|c|c|c|c|c|c|}
\hline & \multicolumn{3}{|l|}{ Total } & \multicolumn{3}{|l|}{ Male } & \multicolumn{3}{|c|}{ Female } \\
\hline & $\beta$ & $95 \%-\mathrm{Cl}$ & $p$-value & $\beta$ & $95 \%-\mathrm{Cl}$ & $p$-value & $\beta$ & $95 \%-\mathrm{Cl}$ & $p$-value \\
\hline \multicolumn{10}{|l|}{$\mathrm{FEV}_{1}^{\mathrm{a}}$} \\
\hline SHS exposure ${ }^{b}$ & -44 & $(-82,-5)$ & 0.03 & -75 & $(-140,-11)$ & 0.02 & -13 & $(-57,31)$ & 0.56 \\
\hline SHS exposure*follow-up time ${ }^{c}$ & 1 & $(0,3)$ & 0.03 & 2 & $(0,4)$ & 0.03 & 1 & $(-1,3)$ & 0.19 \\
\hline \multicolumn{10}{|l|}{$\mathrm{FVC}^{\mathrm{a}}$} \\
\hline SHS exposure ${ }^{b}$ & -56 & $(-102,-10)$ & 0.02 & -102 & $(-179,-24)$ & 0.01 & -19 & $(-71,33)$ & 0.47 \\
\hline SHS exposure*follow-up time ${ }^{c}$ & 2 & $(0,4)$ & 0.02 & 3 & $(0,6)$ & 0.03 & 2 & $(0,4)$ & 0.09 \\
\hline \multicolumn{10}{|l|}{$\mathrm{FEV}_{1} / \mathrm{FVC}^{\mathrm{a}}$} \\
\hline SHS exposure ${ }^{b}$ & 0.0 & $(-0.5,0.5)$ & 0.96 & 0.1 & $(-0.6,0.9)$ & 0.71 & 0.1 & $(-0.6,0.7)$ & 0.88 \\
\hline SHS exposure*follow-up time ${ }^{c}$ & 0.0 & $(0.0,0.0)$ & 0.94 & 0.0 & $(0.0,0.0)$ & 0.96 & 0.0 & $(0.0,0.0)$ & 0.62 \\
\hline \multicolumn{10}{|c|}{$\begin{array}{l}\text { Models are adjusted for age, age squared, weight, weight squared, height, combination of smoking status and pack years, maternal smoking, paternal smoking, } \\
\text { allergic sensitisation, education and exposure to dust/fumes as well as for sex in the total study population } \\
\text { a an interaction term between time between follow-ups and SHS exposure is included to determine the effect of SHS exposure on lung function decline } \\
\text { ba negative estimate suggests that those exposed to SHS at the first examination had lower average lung function at all three examinations than those } \\
\text { not exposed } \\
\text { ca negative estimate suggests that those exposed to SHS at the first examination had a higher decline in lung function between the examinations than those } \\
\text { not exposed }\end{array}$} \\
\hline
\end{tabular}

in FVC. The $\mathrm{FEV}_{1} / \mathrm{FVC}$ ratio will decrease because of loss of lung elastic recoil, a sine qua non of COPD [33, 34] but early in the disease the decrease in FVC may exceed that in $\mathrm{FEV}_{1}$ with a paradoxical effect on the $\mathrm{FEV}_{1} / \mathrm{FVC}$ ratio. This may explain why we did not see an association with COPD defined by spirometric lung function parameters.

A reduced $\mathrm{FEV}_{1}$ and $\mathrm{FVC}$ over time was observed for those reporting exposure to second-hand smoke at the first examination, with stronger effects for males compared to females. Several studies have investigated the association between second-hand smoke exposure and lung function, suggesting sex differences in vulnerability [35-38]. However, the findings are inconsistent. Some studies found adverse effects of passive smoking on spirometric lung function parameters for both sexes [35, 38], whereas another study found stronger effects for women compared to men [36]. Our results are consistent with findings of the study conducted by Masjedi et al. [37] showing a negative association between second-hand smoke exposure and lung function among men, but not among women.

Janson et al. [39] investigated changes and determinants for changes in active as well as passive smoking in the first and second survey of the European Community Respiratory Health Survey showing that exposure to second-hand smoke was higher among subjects with lower socio-economic status and educational level. Furthermore, subjects exposed to second-hand smoke were less likely to quit smoking suggesting that a decrease in second-hand smoke exposure might be effective in decreasing active smoking. In our study, exposure to second-hand smoke decreased during the 20 years of follow-up where for many of the study centres the decrease between the second 10 year follow-up period was stronger compared to the first 10 year period. However, second-hand smoke exposure was still present in all participating centres.

\section{Strengths and limitations}

The European Community Respiratory Health Survey has a longitudinal study design with two follow-ups approximately 10 and 20 years, respectively, after the first survey and therefore we can model the association between changes in second-hand smoke exposure over time with respiratory health outcomes. We are also able to investigate the effect of exposure to second-hand smoke at baseline on lung function decline using spirometric measurements that were performed and quality controlled according to well established guidelines. Also the large study population of around 2000 never-smoking study participants and the high number of participating centres and countries are further strengths.

However this study has some limitations. The information on second-hand smoke exposure as well as respiratory symptoms and diseases was obtained using self-administered questionnaires completed at follow-up and no biomarkers for exposure to second-hand smoke were available. Moreover, the information on second-hand some exposure was only requested for the last 12 months at each survey and not for the total study period. Furthermore, information on the number of cigarettes smoked by other people was not available. No dose-related association between second-hand smoke exposure and respiratory health has been investigated which has to be taken into account when drawing conclusions.

In addition, against a backdrop of falling smoking rates and smoke free legislation across Europe only a small 
proportion of the study group became newly exposed to second-hand smoke over the period of the study. Questionnaire-based information on second-hand smoke exposure might be prone to reporting bias as subjects having respiratory symptoms or diseases might tend to be more affected. Siroux et al. [40] has found no indication that asthma status influences reporting of exposure to second-hand smoke in childhood or adulthood but we cannot exclude that our results are related to reporting biases. The use of different spirometers across study centres and surveys could have resulted in temporal differences in lung function measurements. Sensitivity analyses using lung function values corrected for this change showed comparable results. Furthermore, it was difficult to disentangle the survey and age effects due to three time points comprising two follow-ups each after approximately 10 years as different findings were observed for the association of new exposure to second-hand smoke between two surveys with respiratory symptoms and diseases at follow-up.

The questions on cough and sputum were only requested for winter and not for summer, as these symptoms are often more worse during the winter months. Furthermore, no information on the change of the ventilation equipment used for air cleaning during the follow-up periods was available and thus could not be considered as potential confounding variable.

\section{Conclusion}

In a longitudinal analysis of adults, following a multi-centre cohort over twenty years, exposure to second-hand smoke decreased substantially during the study period. Secondhand smoke exposure in adults was associated with an increased risk for asthma and chronic bronchitis. Our results support further restrictions on smoking in public places.

\section{Additional file}

Additional file 1: Table S1. Associations between change in second-hand smoke (SHS) exposure over time and lung function at follow-up [percent predicted values according to the Global Lung function Initiative - GLI]. (DOCX $18 \mathrm{~kb})$

\section{Acknowledgements}

ECRHS I coordinating centre and project management group

Coordinating Centre (London): P Burney, S Chinn, C Luczynska, D Jarvis, E Lai. Project Management Group: P Burney (Project leader UK), S Chinn (UK), C Luczynska (UK), D Jarvis (UK), P Vermeire (Antwerp), H Kesteloot (Leuven), J Bousquet (Montpellier), D Nowak (Hamburg), J Prichard (Dublin), R de Marco (Verona), B Rijcken (Groningen), JM Anto (Barcelona), J Alves (Oporto), G Boman (Uppsala), N Nielsen (Copenhagen), P Paoletti (Pisa). ECRHS II principal investigators and senior scientific teams Australia (M. Abramson, E.H Walters, J. Raven); Belgium: South Antwerp and Antwerp City (P. Vermeire, J. Weyler, M. van Sprundel, V. Nelen); Estonia: Tartu (R. Jõgi, A. Soon); France: Paris (F. Neukirch, B. Leynaert, R. Liard, M. Zureik), Grenoble (I. Pin, J. Ferran-Quentin); Germany: Erfurt (J. Heinrich, M. Wjst, C. Frye, I. Meyer); Iceland: Reykjavik (T. Gislason, E. Bjornsson, D. Gislason,
K.B Jörundsdóttir); Italy: Turin (R. Bono, M. Bugiani, P.Piccioni, E. Caria, A. Carosso, E. Migliore, G. Castiglioni), Verona (R. de Marco, G. Verlato, E. Zanolin, S. Accordini, A. Poli, V. Lo Cascio, M. Ferrari, I. Cazzoletti), Pavia (A. Marinoni, S. Villani, M. Ponzio, F. Frigerio, M. Comelli, M. Grassi, I. Cerveri, A. Corsico); Norway: Bergen (A. Gulsvik, E. Omenaas, C. Svanes, B. Laerum); Spain: Albacete (J. Martinez-Moratalla Rovira, E. Almar, M. Arévalo, C. Boix, G González, J.M. Ignacio García, J. Solera, J Damián), Galdakao (N. Muñozguren, J. Ramos, I. Urrutia, U. Aguirre), Barcelona (J. M. Antó, J. Sunyer, M. Kogevinas, J. P. Zock, X. Basagaña, A. Jaen, F. Burgos, C. Acosta), Huelva (J. Maldonado, A. Pereira, J.L. Sanchez), Oviedo (F. Payo, I. Huerta, A. de la Vega, L Palenciano, J Azofra, A Cañada); Sweden: Göteborg (K. Toren,L. Lillienberg, A. C. Olin, B. Balder, A. Pfeifer-Nilsson, R. Sundberg), Umea (E. Norrman, M. Soderberg, K. Franklin, B. Lundback, B. Forsberg, L. Nystrom), Uppsala (C. Janson, G. Boman, D. Norback, G. Wieslander, M. Gunnbjornsdottir); Switzerland: Basel (N. Kuenzli, B. Dibbert, M. Hazenkamp, M. Brutsche, U. Ackermann-Liebrich); United Kingdom: Ipswich (D. Jarvis, R. Hall, D. Seaton), Norwich (D. Jarvis, B. Harrison).

ECRHS III principal investigators and senior scientific teams

Australia: Melbourne (M. Abramson, G. Benke, S. Dharmage, B. Thompson,

S. Kaushik); Belgium: South Antwerp \& Antwerp City (J. Weyler,

M. van Sprundel, V. Nelen, E. Van de Mieroop); France: Bordeaux (C. Raherison,

P.O Girodet), Grenoble (I. Pin, V. Siroux, J.Ferran, J.L Cracowski), Montpellier

(P. Demoly, A.Bourdin, I. Vachier), Paris (B. Leynaert, D. Soussan, D. Courbon, C. Neukirch, L. Alavoine, X. Duval, I. Poirier); Germany: Erfurt (J. Heinrich,

E. Becker, G. Woelke, O. Manuwald), Hamburg (H. Magnussen, D. Nowak, A-M Kirsten); Iceland: Reykjavik (T. Gislason, B. Benediktsdottir, D. Gislason, E.S Arnardottir, M. Clausen, G. Gudmundsson, L. Gudmundsdottir, H. Palsdottir, K. Olafsdottir, S. Sigmundsdottir, K. Bara-Jörundsdottir); Italy: Pavia (I. Cerveri, A.Corsico, A. Grosso, F. Albicini, E. Gini, E.M Di Vincenzo, V. Ronzoni, S. Villani, F. Campanella, F. Manzoni, L. Rossi, O. Ferraro), Turin (M. Bugiani, R. Bono,

P. Piccioni, R. Tassinari, V. Bellisario), Verona (R de Marco, S. Accordini, L. Calciano, L. Cazzoletti, M. Ferrari, A.M Fratta Pasini, F. Locatelli, P. Marchetti, A. Marcon, E. Montoli, G. Nguyen, M. Olivieri, C. Papadopoulou, C.Posenato, G. Pesce, P. Vallerio, G. Verlato, E. Zanolin); Norway: (C. Svanes, E. Omenaas, A. Johannessen, T. Skorge, F. Gomez Real); Spain: Albacete (J. Martinez-Moratalla Rovira, E. Almar, A. Mateos, S. García, A. Núñez, P.López, R. Sánchez, E Mancebo), Barcelona (J M. Antó, J.P Zock, J. Garcia-Aymerich, X. Basagaña, F. Burgos, C. Sanjuas, S Guerra), Galdakao (N. Muñozguren, I. Urrutia, U. Aguirre, S. Pascual), Huelva (J Antonio Maldonado, A. Pereira, J. Luis Sánchez, L. Palacios), Oviedo (F. Payo, I. Huerta, N. Sánchez, M. Fernández, B. Robles); Sweden: Göteborg (K. Torén, M. Holm, J-L Kim, A-C Olin, A. Dahlman-Höglund), Umea (B. Forsberg, L. Braback, E. Norrman, L. Modig, B. Järvholm, H. Bertilsson, K. Franklin, C. Wahlgreen, M. Soderberg) Uppsala (B. Andersson, D. Norback, U. Spetz Nystrom,

G. Wieslander, G.M Bodinaa Lund, K. Nisser); Switzerland: Basel (N.M. Probst-Hensch, N. Künzli, D. Stolz, C. Schindler, T. Rochat, J.M. Gaspoz, E. Zemp Stutz, M. Adam, C. Autenrieth, I. Curjuric, J. Dratva, A. Di Pasquale, R. Ducret-Stich, E. Fischer, L. Grize, A. Hensel, D. Keidel, A. Kumar, M. Imboden, N. Maire, A. Mehta, H. Phuleria, M. Ragettli, M. Ritter, E. Schaffner, G.A Thun, A. Ineichen, T. Schikowski, M. Tarantino, M. Tsai); UK: Ipswich (N. Innes), Norwich (A. Wilson).

\section{Funding}

ECRHS I financial support

The following grants helped to fund the local studies.

Australia: Asthma Foundation of Victoria, Allen and Hanbury's; Belgium: Belgian Science Policy Office, National Fund for Scientific Research; Estonia: Estonian Science Foundation, grant no 1088; France: Ministère de la Santé, Glaxo France, Insitut Pneumologique d'Aquitaine, Contrat de Plan Etat-Région Languedoc-Rousillon, CNMATS, CNMRT (90MR/10, 91AF/6), Ministre delegué de la santé, RNSP, France; GSF; Germany: Bundesminister für Forschung und Technologie; Italy: Ministero dell'Università e della Ricerca Scientifica e Tecnologica, CNR, Regione Veneto grant RSF n. 381/05.93; Norway: Norwegian Research Council project no. 101422/310; Spain: Fondo de Investigación Sanitaria (\#91/0016-060-05/E, 92/0319 and \#93/0393), Hospital General de Albacete, Hospital General Juan Ramón Jiménez, Dirección Regional de Salud Pública (Consejería de Sanidad del Principado de Asturias), CIRIT (1997 SGR 00079) and Servicio Andaluz de Salud; Sweden: The Swedish Medical Research Council, the Swedish Heart Lung Foundation, the Swedish Association against Asthma and Allergy; Switzerland: Swiss national Science Foundation grant 4026-28099; UK: National Asthma Campaign, British Lung Foundation, Department of Health, South Thames Regional Health Authority.

The co-ordination of this work was supported by the European Commission. 
ECRHS II financial support

The following grants helped to fund the local studies

Australia: National Health and Medical Research Council; Belgium: Antwerp: Fund for Scientific Research (grant code, G.0402.00), University of Antwerp, Flemish Health Ministry; Estonia: Tartu Estonian Science Foundation grant no 4350; France: Bordeaux: Institut Pneumologique d'Aquitaine; Grenoble: Programme Hospitalier de Recherche Clinique - Direction de la Recherche Clinique (DRC) de Grenoble 2000 number 2610, Ministry of Health, Ministere de l'Emploi et de la Solidarite, Direction Generale de la Sante, Centre Hospitalier Universitaire (CHU) de Grenoble, Comite des Maladies Respiratoires de I'Isere; Montpellier: Programme Hospitalier de Recherche Clinique - DRC de Grenoble 2000 number 2610, Ministry of Health, Direction de la Recherche Clinique, CHU de Grenoble, Ministere de l'Emploiet de la Solidarite, Direction Generale de la Sante, Aventis (France), Direction Regionale des Affaires Sanitaires et Sociales Languedoc-Roussillon; Paris: Ministere de l'Emploi et de la Solidarite, Direction Generale de la Sante,Union Chimique Belge- Pharma (France), Aventis (France), Glaxo France, Programme Hospitalier de Recherche Clinique - DRC de Grenoble 2000 number 2610, Ministry of Health, Direction de la Recherche Clinique, CHU de Grenoble: Germany: Erfurt: GSF - National Research Centre for Environment and Health, Deutsche Forschungsgemeinschaft (grant code, FR1526/1-1); Hamburg: GSF - National Research Centre for Environment and Health, Deutsche Forschungsgemeinschaft (grant code, MA 711/4-1); Iceland: Reykjavik: Icelandic Research Council, Icelandic University Hospital Fund; Italy: Pavia: GlaxoSmithKline Italy, Italian Ministry of University and Scientific and Technological Research (MURST), Local University Funding for Research 1998 and 1999; Turin: Azienda Sanitaria Locale 4 Regione Piemonte (Italy), Azienda Ospedaliera Centro Traumatologico Ospedaliero/Centro Traumatologico Ortopedico-Istituto Clinico Ortopedico Regina Maria Adelaide Regione Piemonte; Verona: Ministero dell'Universita' e della Ricerca Scientifica (MURST), Glaxo Wellcome spa: Norway: Bergen: Norwegian Research Council, Norwegian Asthma and Allergy Association, Glaxo Wellcome AS, Norway Research Fund; Spain: Fondo de Investigacion Santarias (grant codes, 97/0035-01,99/0034-01 and 99/0034 02), HospitalUniversitario de Albacete, Consejeria deSanidad; Barcelona: Sociedad Espanola de Neumologı'a y Cirugía Toracica, Public Health Service (grant code, R01 HL62633-01), Fondo de Investigaciones Santarias (grant codes, 97/0035-01, 99/0034-01, and 99/0034-02), Consell Interdepartamentalde Recerca i Innovacio' Tecnolo'gica (grant code, 1999SGR 00241) Instituto de Salud Carlos III; Red deCentros de Epidemiologı́a y Salud Pu'blica, C03/09,Redde Basesmoleculares y fisiolo'gicas de lasEnfermedadesRespiratorias,C03/011 and Red de Grupos Infancia y Medio Ambiente G03/176; Huelva: Fondo de Investigaciones Santarias (grant codes, 97/0035-01, 99/0034-01, and 99/0034-02); Galdakao: Basque Health Department; Oviedo: Fondo de Investigaciones Sanitaria (97/0035-02, 97/0035, 99/0034-01, 99/0034-02, 99/0034-04, 99/0034-06, 99/350, 99/0034--07), European Commission (EU-PEAL PL01237), Generalitat de Catalunya (CIRIT 1999 SGR 00214), Hospital Universitario de Albacete, Sociedad Española de Neumología y Cirugía Torácica (SEPAR R01 HL62633-01) Red de Centros de Epidemiología y Salud Pública (C03/09), Red de Bases moleculares y fisiológicas de las Enfermedades Respiratorias (C03/011) and Red de Grupos Infancia y Medio Ambiente (G03/176; 97/0035-01, 99/0034-01, and 99/0034-02); Sweden: Göteborg, Umea, Uppsala: Swedish Heart Lung Foundation, Swedish Foundation for Health Care Sciences and Allergy Research, Swedish Asthma and Allergy Foundation, Swedish Cancer and Allergy Foundation, Swedish Council for Working Life and Social Research (FAS); Switzerland: Basel: Swiss National Science Foundation, Swiss Federal Office for Education and Science, Swiss National Accident Insurance Fund; UK: Ipswich and Norwich: Asthma UK (formerly known as National Asthma Campaign).

ECRHS III financial support

The following grants helped to fund the local studies.

Australia: National Health \& Medical Research Council; Belgium: Antwerp South, Antwerp City: Research Foundation Flanders (FWO), grant code G.0.410.08.N.10 (both sites); Estonia: Tartu: SF0180060s09 from the Estonian Ministry of Education; France (All): Ministère de la Santé. Programme Hospitalier de Recherche Clinique (PHRC) national 2010; Bordeaux: INSERM U897 Université Bordeaux segalen; Grenoble: Comitee Scientifique AGIRadom 2011; Paris: Agence Nationale de la Santé, Région lle de France, domaine d'intérêt majeur (DIM); Germany: Erfurt: German Research Foundation HE 3294/10-1; Hamburg: German Research Foundation MA 711/6-1, NO 262/7-1; Iceland: Reykjavik: The Landspitali University Hospital Research Fund, University of Iceland Research Fund, ResMed Foundation, California, USA, Orkuveita
Reykjavikur (Geothermal plant), Vegagerðin (The Icelandic Road Administration (ICERA). Italy: All Italian centres were funded by the Italian Ministry of Health, Chiesi Farmaceutici SpA, in addition Verona was funded by Cariverona foundation, Education Ministry (MIUR); Norway: Norwegian Research council grant no 214123, Western Norway Regional Health Authorities grant no 911631 , Bergen Medical Research Foundation; Spain: Fondo de Investigación Sanitaria (PS09/02457, PS09/00716 09/01511, PS09/02185 PS09/03190), Servicio Andaluz de Salud, Sociedad Española de Neumología y Cirurgía Torácica (SEPAR 1001/ 2010); Barcelona: Fondo de Investigación Sanitaria (FIS PS09/00716); Galdakao: Fondo de Investigación Sanitaria (FIS 09/01511); Huelva: Fondo de Investigación Sanitaria (FIS PS09/02185) and Servicio Andaluz de Salud; Oviedo: Fondo de Investigación Sanitaria (FIS PS09/03190); Sweden: All centres were funded by The Swedish Heart and Lung Foundation, The Swedish Asthma and Allergy Association, The Swedish Association against Lung and Heart Disease. Swedish Research Council for health, working life and welfare (FORTE); Göteborg: also received further funding from the Swedish Council for Working life and Social Research; Umea: also received funding from Vasterbotten Country Council ALF grant; Switzerland: The Swiss National Science Foundation (grants no 33CSCO134276/1, 33CSCO-108796, 3247BO-104283, 3247BO-104288, 3247BO-104284, 3247-065896, 3100-059302, 3200-052720, 3200-042532, 4026-028099) The Federal office for forest, environment and landscape, The Federal Office of Public Health, The Federal Office of Roads and Transport, the canton's government of Aargan, Basel-Stadt, Basel-Land, Geneva, Luzern, Ticino, Valais and Zürich, the Swiss Lung League, the canton's Lung League of Basel Stadt/ Basel, Landschaft, Geneva, Ticino, Valais and Zurich, SUVA, Freiwillige Akademische Gesellschaft, UBS Wealth Foundation, Talecris Biotherapeutics GmbH, Abbott Diagnostics, European Commission 018996 (GABRIEL), Wellcome Trust WT 084703MA; UK: Medical Research Council (MRC), support of the National Institute for Health Research through the Primary Care Research Network.

\section{Availability of data and materials}

The datasets used and analysed during the current study are available from the authors upon reasonable request.

\section{Authors' contributions}

$\mathrm{JH}$ and CF designed the study. CF conducted the statistical analyses and wrote the initial draft. All authors provided substantial contributions to the conception or design of the work, the acquisition, analysis or interpretation of data, revised the manuscript and approved the final version.

\section{Ethics approval and consent to participate}

Local ethics committees at each centre approved the study protocols, and all the participants gave their written informed consent.

\section{Consent for publication}

Not applicable.

\section{Competing interests}

The authors declare that they have no competing interests.

\section{Publisher's Note}

Springer Nature remains neutral with regard to jurisdictional claims in published maps and institutional affiliations.

\section{Author details}

${ }^{1}$ Institute of Epidemiology, Helmholtz Zentrum München - German Research Center for Environmental Health, Ingolstädter Landstraße 1, 85764 Neuherberg, Germany. ${ }^{2}$ Barcelona Institute for Global Health (ISGlobal), Barcelona, Spain. ${ }^{3}$ Universitat Pompeu Fabra (UPF), Barcelona, Spain. ${ }^{4} \mathrm{CIBER}$ Epidemiología y Salud Pública (CIBERESP), Madrid, Spain. ${ }^{5}$ MRC-PHE Centre for Environment and Health, Imperial College London, London, UK. ${ }^{6}$ National Heart and Lung Institute, Imperial College London, London, UK. ${ }^{7}$ Unit of Epidemiology and Medical Statistics, Department of Diagnostics and Public Health, University of Verona, Verona, Italy. ${ }^{8}$ University Hospital of Verona, Verona, Italy. ${ }^{9}$ School of Public Health and Preventive Medicine, Monash University, Melbourne, Australia. ${ }^{10}$ Department of Public Health, Aarhus University, Aarhus, Denmark. ${ }^{11}$ Centre for International Health, University of Bergen, Bergen, Norway. ${ }^{12}$ Department of Occupational Medicine, Haukeland University Hospital, Bergen, Norway. ${ }^{13}$ Department of Occupational and Environmental Medicine, Sahlgrenska University Hospital, Gothenburg, 
Sweden. ${ }^{14}$ Institute and Outpatient Clinic for Occupational, Social and Environmental Medicine, University Hospital Munich (LMU), Munich, Germany. ${ }^{15}$ Comprehensive Pneumology Center Munich (CPC-M), Member of the German Center for Lung Research (DZL), Munich, Germany. ${ }^{16}$ Lung Clinic, Tartu University Clinics, Tartu, Estonia. ${ }^{17}$ Servicio de Neumología del Complejo, Servicio de Salud de Castilla - La Mancha (SESCAM), Hospitalario Universitario de Albacete, Albacete, Spain. ${ }^{18}$ Facultad de Medicina de Albacete, Universidad de Castilla - La Mancha, Albacete, Spain. ${ }^{19}$ Department of Pulmonology, Division of Allergy, Hôpital Arnaud de Villeneuve, University Hospital of Montpellier, Montpellier, France. ${ }^{20}$ Inserm, Sorbonne Université, Equipe EPAR - IPLESP, Paris, France. ${ }^{21}$ Department of Medical Sciences, Respiratory, Allergy and Sleep Research, Uppsala University, Uppsala, Sweden. ${ }^{22}$ Department of Sleep, Landspitali National University Hospital of Iceland, Reykjavik, Iceland. ${ }^{23}$ Faculty of Medicine, University of Iceland, Reykjavik, Iceland. ${ }^{24}$ Department of Public Health and Pediatrics, University of Turin, Turin, Italy. ${ }^{25}$ Department of Occupational and Environmental Medicine, Sahlgrenska University Hospital, Gothenburg, Sweden. ${ }^{26}$ Department of Surgical and Perioperative Sciences, Surgery, Umea University, Umea, Sweden. ${ }^{27}$ Institute for Advanced Biosciences, UGA-Inserm U1209-CNRS UMR 5309, Joint Research Center, Team of Environmental Epidemiology Applied to Reproduction and Respiratory Health, Site Santé - Allée des Alpes, 38700 La Tronche, Grenoble, France. ${ }^{28}$ Inserm, UMR 1152, Pathophysiology and Epidemiology of Respiratory Diseases, Paris, France, UMR 1152, University Paris Diderot Paris, Paris, France. ${ }^{29}$ Pulmonology Department,

Galdakao-Usansolo Hospital, Galdakao, Biscay, Spain. ${ }^{30}$ Division of Respiratory Diseases, IRCCS Policlinico San Matteo Foundation, Pavia, Italy. ${ }^{31}$ Department of Internal Medicine and Therapeutics, University of Pavia, Pavia, Italy. ${ }^{32}$ Respiratory and Allergy Clinical Unit, Universitary Hospitalary Complex, Huelva, Spain. ${ }^{33}$ Swiss Tropical and Public Health Institute, Basel, Switzerland. ${ }^{34}$ Department of Public Health, University of Basel, Basel, Switzerland. ${ }^{35}$ Pulmonary Department, Hospital Galdakao, Galdakao, Biscay, Spain. ${ }^{36}$ Allergy and Lung Health Unit, Melbourne School of Population and Global Health, The University of Melbourne, Melbourne, Australia.

\section{Received: 26 October 2018 Accepted: 4 February 2019}

\section{Published online: 14 February 2019}

\section{References}

1. Oberg M, Jaakkola MS, Woodward A, Peruga A, Prüss-Ustün A. Worldwide burden of disease from exposure to second-hand smoke: a retrospective analysis of data from 192 countries. Lancet. 2011;377(9760):139-46.

2. Strachan DP, Cook DG. Health effects of passive smoking. 5. Parental smoking and allergic sensitisation in children. Thorax. 1998;53:117-23.

3. Strachan DP, Cook DG. Health effects of passive smoking. 6. Parental smoking and childhood asthma: longitudinal and case-control studies. Thorax. 1998 Mar;53:204-12.

4. Cook DG, Strachan DP, Carey IM. Health effects of passive smoking. 9. Parental smoking and spirometric indices in children. Thorax. 1998;53:884-93.

5. Cook DG, Strachan DP. Health effects of passive smoking. 10. Summary of effects of parental smoking on the respiratory health of children and implications for research. Thorax. 1999;54:357-66.

6. Eisner MD, Balmes J, Katz PP, Trupin L, Yelin EH, Blanc PD. Lifetime environmental tobacco smoke exposure and the risk of chronic obstructive pulmonary disease. Environ Health. 2005;4(1):7.

7. Sobonya R, Burrows B. The epidemiology of emphysema. Clin Chest Med. 1983:4(3):351-8.

8. Yin P, Jiang CQ, Cheng KK, Lam TH, Lam KH, Miller MR, et al. Passive smoking exposure and risk of COPD among adults in China: the Guangzhou biobank cohort study. Lancet. 2007;370(9589):751-7.

9. Chan-Yeung M, Ho ASS, Cheung AHK, Liu RWT, Yee WKS, Sin KM, et al. Determinants of chronic obstructive pulmonary disease in Chinese patients in Hong Kong. Int J Tuberc Lung Dis. 2007;11(5):502-7.

10. McGhee SM, Ho SY, Schooling M, Ho LM, Thomas GN, Hedley AJ, et al. Mortality associated with passive smoking in Hong Kong. BMJ. 2005;330(7486):287-8.

11. Fischer F, Kraemer A. Meta-analysis of the association between second-hand smoke exposure and ischaemic heart diseases. COPD and stroke BMC Public Health. 2015;15:1202.

12. Janson C, Chinn S, Jarvis D, Zock JP, Torén K, Burney P, et al. Effect of passive smoking on respiratory symptoms, bronchial responsiveness, lung function, and total serum lgE in the European Community respiratory health survey: a cross-sectional study. Lancet. 2001;358(9299):2103-9.

13. Accordini S, Calciano L, Johannessen A, Portas L, Benediktsdottir B, Bertelsen RJ, et al. A three-generation study on the association of tobacco smoking with asthma. Int J Epidemiol. 2018;47:1106-17.

14. Svanes C, Sunyer J, Plana E, Dharmage S, Heinrich J, Jarvis D, et al. Early life origins of chronic obstructive pulmonary disease. Thorax. 2010;65:14-20.

15. Allinson JP, Hardy R, Donaldson GC, Shaheen SO, Kuh D, Wedzicha JA. Combined impact of smoking and early-life exposures on adult lung function trajectories. Am J Respir Crit Care Med. 2017;196:1021-30.

16. Regan EA, Lynch DA, Curran-Everett D, Curtis JL, Austin JHM, Grenier PA, et al. Clinical and radiologic disease in smokers with normal spirometry. JAMA Intern Med. 2015;175(9):1539-49.

17. Woodruff PG, Barr RG, Bleecker E, Christenson SA, Couper D, Curtis JL, et al. Clinical significance of symptoms in smokers with preserved pulmonary function. N Engl J Med. 2016;374(19):1811-21.

18. European Community Respiratory Health Survey II Steering Committee. The European Community respiratory health survey II. Eur Respir J. 2002;20(5):1071-9.

19. Burney PG, Luczynska C, Chinn S, Jarvis D. The European Community respiratory health survey. Eur Respir J. 1994;7(5):954-60.

20. Sunyer J, Pekkanen J, Garcia-Esteban R, Svanes C, Künzli N, Janson C, et al. Asthma score: predictive ability and risk factors. Allergy. 2007;62:142-8.

21. Miller MR, Hankinson J, Brusasco V, Burgos F, Casaburi R, Coates A, et al. Standardisation of spirometry. Eur Respir J. 2005;26:319-38.

22. Quanjer PH, Stanojevic S, Cole TJ, Baur X, Hall GL, Culver BH, et al. Multiethnic reference values for spirometry for the 3-95-yr age range: the global lung function 2012 equations. Eur Respir J. 2012;40(6):1324-43.

23. Fuertes $E$, Carsin $A E$, Antó JM, Bono R, Corsico AG, Demoly P, et al. Leisure-time vigorous physical activity is associated with better lung function: the prospective ECRHS study. Thorax. 2018;73:376-84.

24. R Core Team. R: A Language and Environment for Statistical Computing. Vienna, Austria; 2017. Available from: https://www.R-project.org/.

25. Coogan PF, Castro-Webb N, Yu J, O'Connor GT, Palmer JR, Rosenberg L. Active and passive smoking and the incidence of asthma in the black Women's health study. Am J Respir Crit Care Med. 2015:191:168-76.

26. Lajunen TK, Jaakkola JJK, Jaakkola MS. The synergistic effect of heredity and exposure to second-hand smoke on adult-onset asthma. Am J Respir Crit Care Med. 2013;188:776-82.

27. Jaakkola MS, Piipari R, Jaakkola N, Jaakkola JJK. Environmental tobacco smoke and adult-onset asthma: a population-based incident case-control study. Am J Public Health. 2003;93:2055-60.

28. Hagstad S, Bjerg A, Ekerljung L, Backman H, Lindberg A, Rönmark E, et al. Passive smoking exposure is associated with increased risk of COPD in never smokers. Chest. 2014;145(6):1298-304.

29. Wu CF. Feng NH, Chong IW, Wu KY, Lee CH, Hwang JJ, et al. Second-hand smoke and chronic bronchitis in Taiwanese women: a health-care based study BMC Public Health. 2010;10:44.

30. Global Initiative for Chronic Obstructive Lung Disease. Pocket guide to COPD diagnosis, management, and prevention. A guide for health care professionals; 2017. Available from: https://goldcopd.org/.

31. Global Initiative for Chronic Obstructive Lung Disease. Global strategy for the diagnosis, management, and prevention of chronic obstructive pulmonary disease; 2006. Available from: https://goldcopd.org/.

32. Pauwels RA, Buist AS, Calverley PM, Jenkins CR, Hurd SS, Committee GS. Global strategy for the diagnosis, management, and prevention of chronic obstructive pulmonary disease. NHLBI/WHO global initiative for chronic obstructive lung disease (GOLD) workshop summary. Am J Respir Crit Care Med. 2001;163:1256-76.

33. Macklem PT. Therapeutic implications of the pathophysiology of COPD. Eur Respir J. 2010;35:676-80.

34. Hogg JC, Paré PD, Hackett TL. The contribution of small airway obstruction to the pathogenesis of chronic obstructive pulmonary disease. Physiol Rev. 2017;97:529-52.

35. Langhammer A, Johnsen R, Gulsvik A, Holmen TL, Bjermer L. Sex differences in lung vulnerability to tobacco smoking. Eur Respir J. 2003;21:1017-23.

36. Eisner MD. Environmental tobacco smoke exposure and pulmonary function among adults in NHANES III: impact on the general population and adults with current asthma. Environ Health Perspect. 2002;1 10:765-70.

37. Masjedi MR, Kazemi $\mathrm{H}$, Johnson DC. Effects of passive smoking on the pulmonary function of adults. Thorax. 1990;45:27-31. 
38. Janzen B, Karunanayake C, Rennie D, Pickett W, Lawson J, Kirychuk S, et al. Gender differences in the association of individual and contextual exposures with lung function in a rural Canadian population. Lung. 2017:195:43-52.

39. Janson C, Künzli N, de Marco R, Chinn S, Jarvis D, Svanes C, et al. Changes in active and passive smoking in the European Community respiratory health survey. Eur Respir J. 2006;27(3):517-24.

40. Siroux V, Guilbert P, Le Moual N, Oryszczyn MP, Kauffmann F. Influence of asthma on the validity of reported lifelong environmental tobacco smoke in the EGEA study. Eur J Epidemiol. 2004;19:841-9.

\section{Ready to submit your research? Choose BMC and benefit from:}

- fast, convenient online submission

- thorough peer review by experienced researchers in your field

- rapid publication on acceptance

- support for research data, including large and complex data types

- gold Open Access which fosters wider collaboration and increased citations

- maximum visibility for your research: over $100 \mathrm{M}$ website views per year

At $\mathrm{BMC}$, research is always in progress.

Learn more biomedcentral.com/submissions 